\title{
Synthesis of nanostructured hollow microspheres of vanadium (III, V) oxides
}

\author{
E. V. Vladimirova, O. I. Gyrdasova, A. V. Dmitriev \\ Institute of Solid State Chemistry, Ural Branch, Russian Academy of Sciences, \\ Pervomayskaya, 91, Yekaterinburg, 620990 Russia \\ Vladimirova@ihim.uran.ru,gyrdasova@ihim.uran.ru,av.dmit.10.10@gmail.com
}

DOI 10.17586/2220-8054-2020-11-5-572-577

\begin{abstract}
Vanadium oxides $\mathrm{V}_{2} \mathrm{O}_{5}$ and $\mathrm{V}_{2} \mathrm{O}_{3}$ have been synthesized by ultrasonic spray pyrolysis in the form of nanostructured spherical agglomerates with an average diameter of $0.5-1.5 \mu \mathrm{m}$. By changing the synthesis conditions, the vanadium oxidation state and microspheres surface morphology can be varied. The microspheres of $\mathrm{V}_{2} \mathrm{O}_{5}$ are formed during aerobic synthesis, while $\mathrm{V}_{2} \mathrm{O}_{3}$ microspheres are produced under an atmosphere of argon. An increase in the concentration of the initial solution leads to an increase in both size of $\mathrm{V}_{2} \mathrm{O}_{5}$ nanoparticles and the diameters of the $\mathrm{V}_{2} \mathrm{O}_{5}$ microspheres. Long-term storage of $\mathrm{V}_{2} \mathrm{O}_{3}$ in air results in morphological degradation of the microspheres.
\end{abstract}

Keywords: nanostructured microspheres, ultrasonic spray pyrolysis, solutions, vanadium oxides.

Received: 9 September 2020

\section{Introduction}

It is known [1] that a number of oxides of 3d-, 4d- and 5f- elements, including vanadium, are capable for metaldielectric phase transition (MDPT) under the influence of temperature and pressure. This phase transition leads to changes in the structural, thermophysical, optical, magnetic and electrical properties of the compound and finds wide practical application. Thus, for $\mathrm{V}_{2} \mathrm{O}_{3}$, a phase transition at $150-160 \mathrm{~K}$ is observed from a low-temperature monoclinic (space group I2/a) to a rhombohedral (space group R3c) modification, which is accompanied by an increase in the electrical conductivity by seven orders of magnitude and a change in magnetic behavior from antiferromagnetic to paramagnetic [2,3]. Therefore, materials based on vanadium (III) oxide are widely used for the manufacture of thermistors with a sharp change in resistance [4], which are used in electronic and electrical devices as breakers and inrush current limiters. In order to control the temperature of the $\mathrm{V}_{2} \mathrm{O}_{3}$ phase transition, the influence of deformation, pressure and doping is studied [5-9]. Several vanadium oxides and vanadium oxide-based compounds have a layered or tunnel type of crystal structure of V-O polyhedra, which provides significant mobility of metal cations embedded in crystallographic lattice [10]. This property makes these compounds a promising material for use as sensor materials and electrodes for intercalation batteries. Therefore, vanadium oxides with mixed valence and their derivatives have recently attracted attention as chemical sensors, nanoscale magnets, and electrical and optical devices [11-13]. The specific interest is the practical application of $\mathrm{V}_{2} \mathrm{O}_{5}$-based solid solutions as highly efficient cathode materials for metal-ion batteries, which demonstrates a high energy density (with charging capacity up to $650 \mathrm{mAh} / \mathrm{g}$ ) and significant cycle stability [14-16]. The nanostructured $\mathrm{V}_{2} \mathrm{O}_{5}$-based materials obtained in the last decade demonstrate an high rate of the intercalation and deintercalation of $\mathbf{M}^{n+}$ ions compared to commercial ones [17]. A large amount of experimental results has been accumulated on the hierarchical structures of nanocrystalline vanadium (V) oxide [18]. Information on the features of the formation of $\mathrm{V}_{2} \mathrm{O}_{3}$ in the nanocrystaline state is scarce and contradictory. Significant differences in the character of MDPT in nanodispersed $\mathrm{V}_{2} \mathrm{O}_{3}$ in comparison with bulk crystalline samples were found [19]. Due to the synergetic effect, three-dimensional (3D) hierarchical nanostructures have a stable structure, a developed surface, and a large number of active centers. Such structures are intensively studied and applied in the field of optics, catalysis, and energy conservation [20]. The morphological features of nanocrystaline samples are varied by the preparation conditions. There are several ways to synthesize vanadium oxides in the 3-D state: hydrothermal method [17], thermal decomposition of complexes with an organic ligand [21], and spray pyrolysis method [22-25]. The production of oxide materials in the form of hollow microspheres is a challenging task, since these objects combine the advantages of 3-D structures and thin films. This work describes the most promising method of ultrasonic spray pyrolysis (USP). Previously, using the USP method, hollow microspheres of multiferroics $\mathrm{BiFe}_{1-x} \mathrm{Mn}_{x} \mathrm{O}_{3} \mathrm{were}$ obtained and studied $[26,27]$. The USP method makes it possible to control the conditions for the formation of a single-phase oxide from an aqueous aerosol with a radial distribution of dissolved components in the droplet volume, which subsequently determines the formation of spherical agglomerates of a given diameter [26]. By varying the intensity of ultrasonic exposure, the temperature and atmosphere of aerosol thermolysis, it seems possible to obtain vanadium oxide in the expected valence and morphological state. 
The aim of this study is to obtain vanadium (III and V) oxides in the form of nanostructured hollow microspheres using the USP method in a controlled gas atmosphere.

\section{Experimental}

Ammonium metavanadate $\mathrm{NH}_{4} \mathrm{VO}_{3}$ was used as a vanadium-containing precursor. Oxalic $\mathrm{C}_{2} \mathrm{H}_{2} \mathrm{O}_{4}$ acid was added to an aqueous solution of $\mathrm{NH}_{4} \mathrm{VO}_{3}$ in a molar ratio of ammonium metavanadate:acid equal to 1:2. The vanadyl ions $\mathrm{VO}^{2+}$ solution with concentration of $0.10-0.30 \mathrm{~mol} / \mathrm{l}$ was subjected to ultrasonic spraying in a vertical tube furnace at a temperature of $550-800^{\circ} \mathrm{C}$. Air or argon was used as a carrier gas at a rate of $0.10-0.20 \mathrm{~m} / \mathrm{s}$. The resulting oxide was collected by an electrostatic precipitator.

The use of the $\mathrm{V}^{4+}$ precursor for the synthesis of vanadium oxides in different oxidation states excludes the stage of reduction of the formed $\mathrm{V}_{2} \mathrm{O}_{5}$ by hydrogen. It is known that the addition of carboxylic acids to the ammonium metavanadate solution ensures the reduction of $\mathrm{VO}_{3}^{-}$ions to $\mathrm{VO}^{2+}$ and stabilizes the vanadyl ion in an aqueous medium in the form of a complex [19]:

$$
\begin{gathered}
\mathrm{VO}_{3}^{-}+2 \mathrm{H}_{2} \mathrm{C}_{2} \mathrm{O}_{4} \rightarrow \mathrm{VO}^{2+}+2 \mathrm{CO}_{2}+\mathrm{C}_{2} \mathrm{O}_{4}^{2-}+2 \mathrm{H}_{2} \mathrm{O} \\
\mathrm{VO}^{2+}+\mathrm{C}_{2} \mathrm{O}_{4}^{2-} \rightarrow\left[\mathrm{VO}^{+}\left(\mathrm{C}_{2} \mathrm{O}_{4}\right)_{2}\right]^{3-}
\end{gathered}
$$

USP synthesis was carried out using gas carrier: air or Ar. The synthesis temperature in both cases was $600^{\circ} \mathrm{C}$. Aerosol was fed into the reaction zone at a rate of $0.2 \mathrm{~m} / \mathrm{s}$, corresponding to a synthesis time of $5 \mathrm{sec}$. A schematic diagram of the of vanadium oxide (III or V) synthesis is shown in Fig. 1.

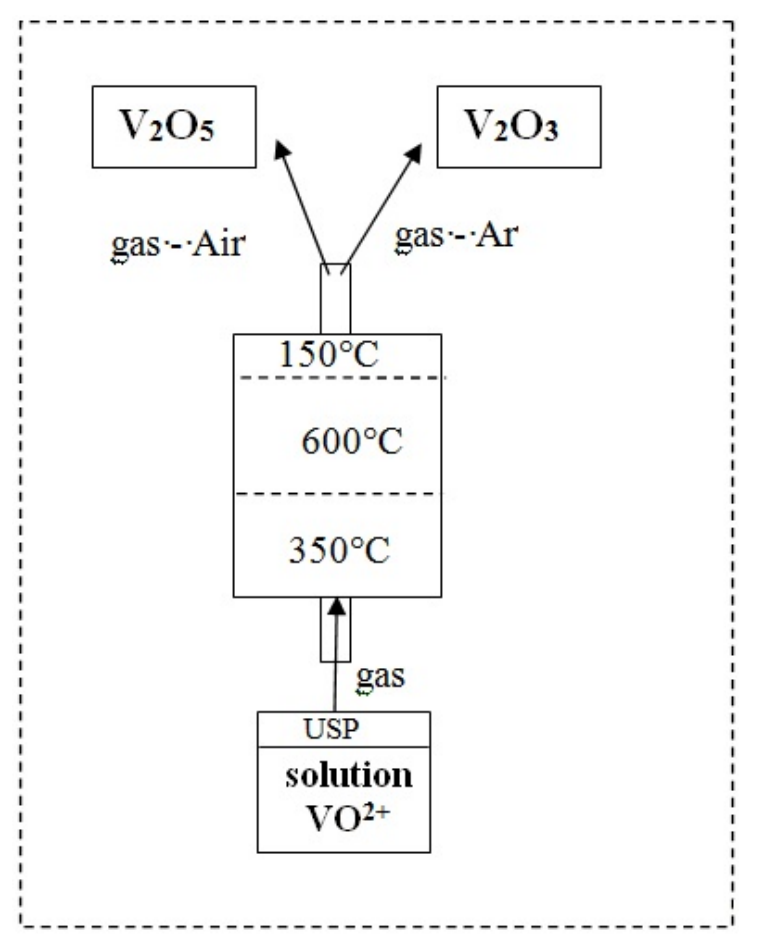

FIG. 1. A schematic diagram of the $\mathrm{V}_{2} \mathrm{O}_{n}$ synthesis

X-ray phase analysis was carried out on an XRD-7000 diffractometer (SHIMADZU) with a secondary monochromator in $\mathrm{CuK} \alpha$ radiation in the $2 \theta$ angle range from $20^{\circ}$ to $80^{\circ}$ with a step of $0.03^{\circ}$. X-ray diffraction analysis was performed using the PowderCell software. The morphology of the samples, their chemical composition and the uniformity of the distribution of chemical elements were studied using a JEOL JSM-6390LA scanning electron microscope (SEM) equipped with an EDS Inca Enegy 250 X-ray spectrometer.

\section{Results and discussion}

Under the described conditions, the single-phase samples of vanadium oxides were obtained. When carrying out the USP process in air the only product was $\mathrm{V}_{2} \mathrm{O}_{5}$. And using Ars a gas carrier the final product was $\mathrm{V}_{2} \mathrm{O}_{3}$. 

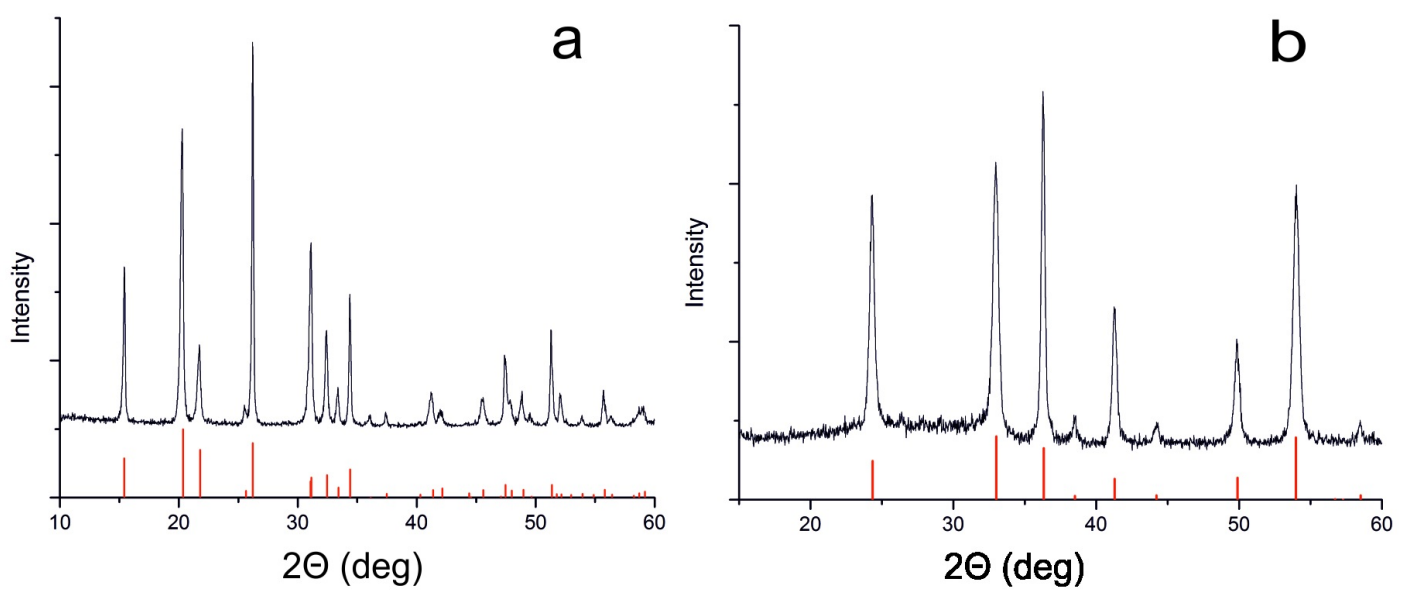

FIG. 2. X-ray diffraction patterns of samples obtained by USP $V^{2+}$ solution: in air (a), in $\operatorname{Ar}(b)$

The diffraction patterns of the samples have a profile characteristic of the corresponding vanadium oxide (ICSD Collection Code 15299) (Fig. 2). During the USP the aerosol particles get directly into the drying zone with a temperature of $250-350{ }^{\circ} \mathrm{C}$, and then into the calcination zone with a temperature of $600{ }^{\circ} \mathrm{C}$ (Fig. 1). The parameters and conditions of USP, i.e. the concentration of vanadyl ion $\mathrm{C}_{V O}^{2+}$ and the suppling rate of solution to the drying zone. These parameters ensure the production of hollow microspheres observed experimentally. The Table 1 shows the effect of the synthesis conditions of $\mathrm{V}_{2} \mathrm{O}_{n}\left(\mathrm{C}_{V O}^{2+}\right)$ on the parameters of unit cells and the size of coherent scattering regions D (Table 1).

TABLE 1. Characteristics of samples obtained from solution

\begin{tabular}{|c|l|c|c|c|c|}
\hline Sample & Synthesis conditions & Oxide composition & Unit cell parameters & $\mathrm{D}, \mu \mathrm{m}$ & $\mathrm{CSR}, \mathrm{nm}$ \\
\hline $\mathrm{I}$ & air & & $a=11.4807$ & 0.45 & 50 \\
& $\mathrm{C}_{V O^{2+}}=0.04 \mathrm{~mol} / \mathrm{l}$ & $\mathrm{V}_{2} \mathrm{O}_{5}$ & $\begin{array}{c}c .5636 \\
b=4.3989\end{array}$ & & \\
& & & $a=11.4863$ & 0.65 & 62 \\
$\mathrm{II}$ & air & & $c=3.5561$ & & \\
& $\mathrm{C}_{V O^{2+}}=0.3 \mathrm{~mol} / \mathrm{l}$ & $\mathrm{V}_{2} \mathrm{O}_{5}$ & $b=4.3792$ & & \\
& & & $a=4.94498$ & 0.45 & 36 \\
\hline III & $\mathrm{Ar}$ & $\mathrm{V}_{2} \mathrm{O}_{3}$ & $b=14.0123$ & & \\
\hline
\end{tabular}

The complex mechanisms of aerosol droplet formation, drying, and thermolysis in a dynamic mode were studied in detail in [26]. It was shown that the morphology of particles when using the USP process is formed during drying and is retained during the subsequent calcination.

It has been experimentally established that the diameter of a spherical particle formed by USP process $d_{g}$ can be expressed by the following theoretical relationship:

$$
d_{g}=d_{D}=\sqrt{\frac{C_{V}}{\rho_{p}}},
$$

where $\mathrm{C}_{V}$ is the vanadium concentration, $\rho_{p}$ is the vanadium oxide density, $d_{D}$ is the average aerosol droplet size.

The droplet size is inversely proportional to the frequency of ultrasonic action on the solution during spraying. The intensity of US-vibrations is determined by the viscosity and surface tension of the liquid used as a precursor.

According to SEM and X-ray phase analysis the average diameter of the regular $\mathrm{V}_{2} \mathrm{O}_{5}$ microspheres obtained from dilute solutions of vanadium in air is $0.45 \mu \mathrm{m}$ of (Fig. 3a). The surface of the spheres is dense, without pores and faults. With an increase in the vanadium concentration in the solution up to $0.3 \mathrm{~mol} / \mathrm{l}$, the average diameter of the resulting spheres grows insignificantly (Table 1, Fig. 2b), and the lattice parameters do not undergo noticeable changes. 

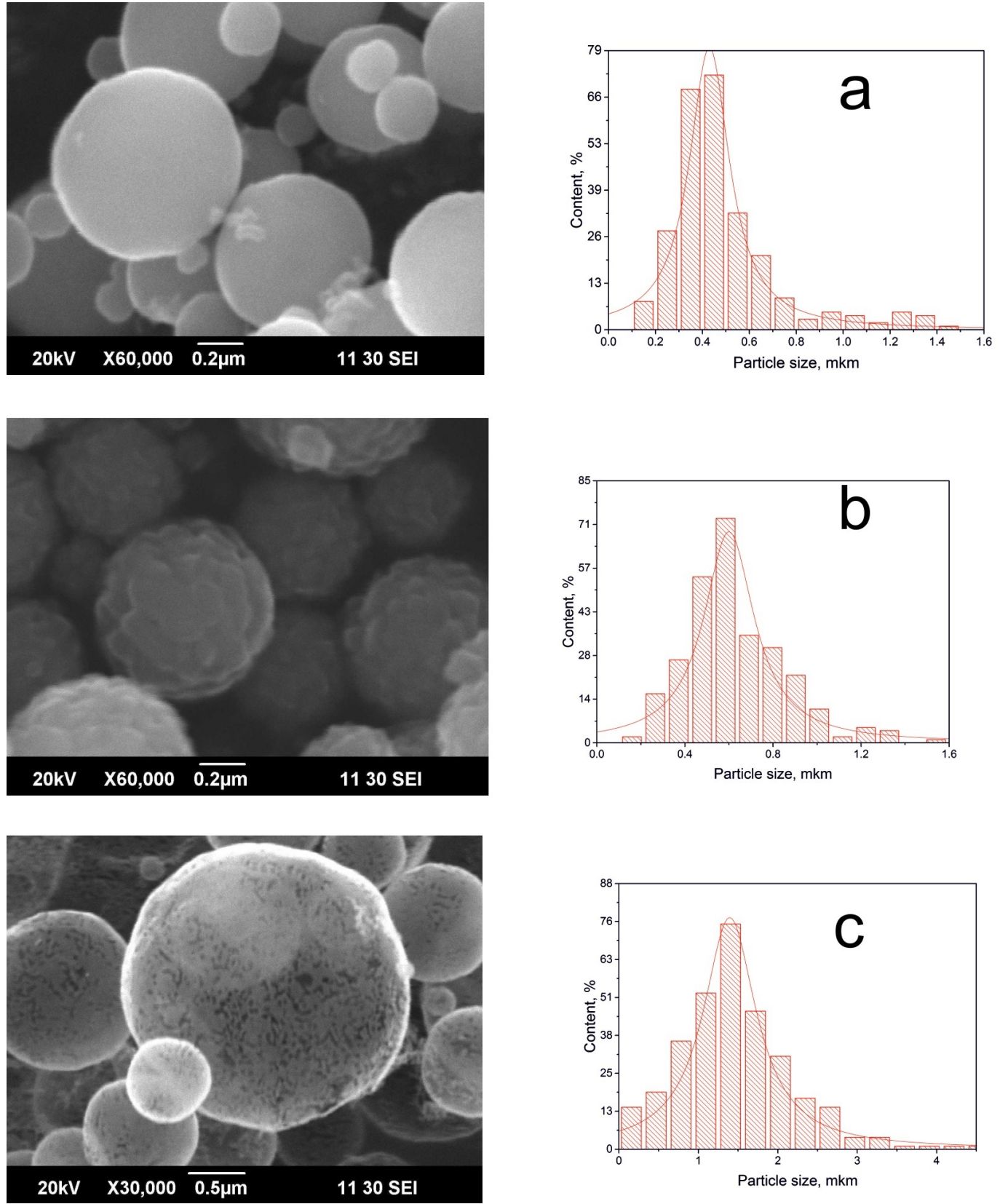

FIG. 3. SEM image and particle size distribution of $\mathrm{V}_{2} \mathrm{O}_{5}$ samples obtained from a solution with a concentration of $0.04 \mathrm{~mol} / \mathrm{l}$ (a) and $0.3 \mathrm{~mol} / \mathrm{l}$ (b) and $\mathrm{V}_{2} \mathrm{O}_{3}$ (c)

The main difference between obtained $\mathrm{V}_{2} \mathrm{O}_{5}$ microspheres is the surface type morphology. The surface of $\mathrm{V}_{2} \mathrm{O}_{5}$ microspheres obtained from concentrated solution is formed by flat scaly crystals closely adjacent to each other (Fig. 3b). In the case of USP under an Ar atmosphere, the $\mathrm{V}_{2} \mathrm{O}_{3}$ microspheres with an average diameter of $1.5 \mu \mathrm{m}$ were obtained (Fig. 3c). The surface of the spheres is loose, formed from one layer of nanosized crystallites. It is known that vanadium (III) oxide is metastable and over time it undergoes spontaneous oxidation to $\mathrm{V}_{2} \mathrm{O}_{5}$ [27, 28]. The process of partial morphological and structural degradation characteristic of $\mathrm{V}_{2} \mathrm{O}_{3}$ was observed after 12 months of storage of the sample in air (Fig. 4).

The so-called "aging" of spherical samples is observed in a significant broadening of diffraction peaks characteristic to the $\mathrm{V}_{2} \mathrm{O}_{3}$ structure (Fig. 4). At the same time, no peaks of the $\mathrm{V}_{2} \mathrm{O}_{5}$ impurity were found in the diffraction patterns. According to SEM data (Fig. 4), the surface of the aged $\mathrm{V}_{2} \mathrm{O}_{3}$ samples is formed by lamellar aggregates connected weakly to each other. Therefore, the shell was easily destroyed and the spheres were completely degraded. 

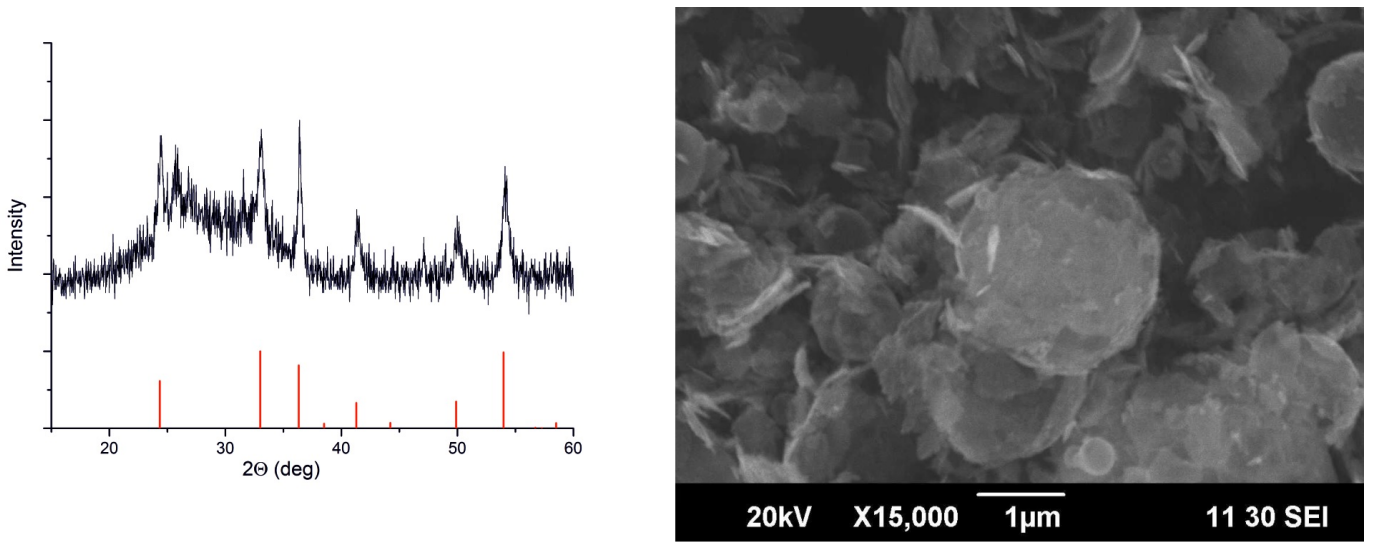

FIG. 4. $\mathrm{V}_{2} \mathrm{O}_{3}$ sample after storage in air: diffraction pattern and SEM image

\section{Conclusion}

Vanadium oxide (III or V), in the form of hollow microspheres, was obtained by the method of ultrasonic spray pyrolysis (USP) in the controlled gas atmosphere at one stage. The size of the microspheres and the main properties of their surface are establish to be dependent on the concentration of the precursor in an aqueous solution and thermolysis atmosphere. Thus, the average diameter of microspheres can be experimentally varied in the range $0.45-1.5 \mu \mathrm{m}$. The surface of $\mathrm{V}_{2} \mathrm{O}_{3}$ spheres obtained in an Ar atmosphere is formed by one layer of crystallites with an average size of $36 \mathrm{~nm}$. Spontaneous oxidation of spherical $\mathrm{V}_{2} \mathrm{O}_{3}$ leads to complete degradation of its surface.

\section{Acknowledgments}

This work was carried out in accordance with the state assignment and research plans of the Institute of Solid State Chemistry of the Ural Branch of the Russian Academy of Sciences (grant No AAAA-A19-119031890026-6, No AAAA-A19-119031890025-9).

\section{References}

[1] Mott N.F. Metal-insulator transitions. Taylor@Francis, London, 1990, 294 p.

[2] Goodenough J.B. Magnetism and the Chemical Bond. J. Appl. Phys., 1968, 39, P. 403.

[3] Carter S.A., Rosenbaum T.F., Honig J.M., and Spalek J. New phase boundary in highly correlated, barely metallic $\mathrm{V}_{2} \mathrm{O}_{3}$. Phys. Rev. Lett., 1991, 67, P. 3440.

[4] Zhang Y., Fan ., Liu X. et al. Beltlike $\mathrm{V}_{2} \mathrm{O}_{3} @ \mathrm{C}$ core-shell-structured composite: design, preparation, characterization, phase transition, and improvement of electrochemical properties of $\mathrm{V}_{2} \mathrm{O}_{3}$. Eur. J. Inorg. Chem., 2012, 10, P. 1650-1659.

[5] Metcalf P.A. et al. Electrical, structural, and optical properties of Cr-doped and non-stoichiometric $\mathrm{V}_{2} \mathrm{O}_{3}$ thin films. Thin Solid Films. 2007, 515(7-8), P. 3421-3425.

[6] Weber D. et al. Bixbyite-Type $\mathrm{V}_{2} \mathrm{O}_{3}$ - A Metastable Polymorph of Vanadium Sesquioxide. Inorganic Chemistry, 2011, 50(14), P. 6762-6766.

[7] Populoh S. et al. The power factor of Cr-doped $\mathrm{V}_{2} \mathrm{O}_{3}$ near the Mott transition. Appl. Phys. Lett., 2011, 99(17), P. 3-7.

[8] Panaccione G. et al. Bulk electronic properties of $\mathrm{V}_{2} \mathrm{O}_{3}$ probed by hard X-ray photoelectron spectroscopy. J. of Electron Spectroscopy and Related Phenomena, 2007, 156-158, P. 64-67

[9] Laad M.S., Craco L., Müller E. Orbital-selective insulator-metal transition in $\mathrm{V}_{2} \mathrm{O}_{3}$ under external pressure. Phys. Rev. B., 2006, 73(4), P. 15-21.

[10] Zavalij P.Y. and Whittingham M.S. Whittingham. Structure chemistry of vanadium oxides with open frameworks. Acta Cryst., 1999, B55, P. 627-630.

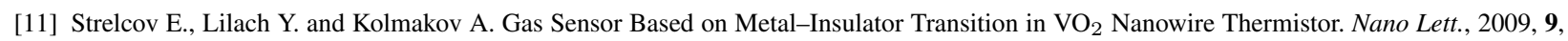
P. 2322-2326

[12] Krusin-Elbaum L., Newns D. M., Zeng H., Derycke V., Sun J.Z. and Sandstrom R. Room-temperature ferromagnetic nanotubes controlled by electron or hole doping. Nature, 2004, 431, P. 672-676.

[13] Vavilova E., Hellmann I., Kataev V., Täschner C., Büchner B. and Klingeler R. Magnetic properties of vanadium oxide nanotubes probed by static magnetization and 51V NMR. Phys. Rev. B, 2006, 73, P. 144417(1-7).

[14] Chen Zh., Augustyn V., Wen J., Zhang Yu., Shen M., Dunn B. and Lu Yu. M. Shen, B. Dunn and Yu. Lu. High Performance Supercapacitors Based on Intertwined CNT/ $\mathrm{V}_{2} \mathrm{O}_{5}$ Nanowire Nanocomposites Adv. Mater., 2011, 23, P. 791-799.

[15] Dong W., Sakamoto J. and Dunn B. Electrochemical Properties of Vanadium Oxide Aerogelsand Aerogel Nanocomposites. J. Sol-Gel Sci. Technol., 2003, 26, P. 641-644.

[16] Yan M., He P., Chen Y., Wang S., Wei Q., Zhao K., Xu X., An Q., Shuang Y., Shao Y., Mueller K.T., Mai L., Liu J., Yang J. Water-lubricated intercalation in $\mathrm{V}_{2} \mathrm{O}_{5} \cdot \mathrm{nH}_{2} \mathrm{O}$ for high-capacity and high-rate aqueous rechargeable zinc batteries. Adv. Mater. $2018,30, \mathrm{P} .1703725$.

[17] Pan J., Li M., Luo Y.Y., Wu H., Zhong L., Wang Q., Li G.H. Synthesis and SERS activity of $\mathrm{V}_{2} \mathrm{O}_{5}$ nanoparticles. Appl. Surf. Sci., 2015, 333, P. 34-38. 
[18] Liu X., Zeng J., Yang H., Zhou K., Pan D. V $2 \mathrm{O}_{5}$-based nanomaterials: synthesis and their applications. $R S C$ Adv., 2018, 8(8), P. 4014-4031.

[19] Blagojevic V.A., Carlo J.P., Brus L.E., Steigerwald M.L., Uemura Y.J., J.L. Billinge, G. M Luke. Magnetic phase transition in $\mathrm{V}_{2} \mathrm{O}_{3}$ nanocrystals. Physical Review B, 2010, 82(9), P. 094453.

[20] Mai L.Q., Tian X.C., Xu X., Chang L., Xu L. Nanowire Electrodes for Electrochemical Energy Storage Devices. Chem.Rev., 2014, 114, P. 11828-11862.

[21] Asim N., Radiman S., Yarmo M.A., BanayeGolriz M.S. Vanadium pentoxide: Synthesis and characterization of nanorod and nanoparticle $\mathrm{V}_{2} \mathrm{O}_{5}$ using CTAB micelle solution. Microporous Mesoporous Mater, 2009, 120, P. 397-401.

[22] Abd-Alghafour N.M., Ahmed N.M., Hassan Z., Mohammad S.M., Bououdina M., Ali M.K.M. Characterization of $\mathrm{V}_{2} \mathrm{O}_{5}$ nanorods grown by spray pyrolysis technique. J. Mater. Sci. - Mater. Electron, 2016, 27, P. 4613-4621.

[23] Zhendong Yin, Jie Xu, Yali Ge et al. Synthesis of $\mathrm{V}_{2} \mathrm{O}_{5}$ microspheres by spray pyrolysis as cathode material for supercapacitors. Mater. Res. Express, 2018, 5(3), P. 036306.

[24] Zhang X.Y., Wang J.G., Liu H.Y., Liu H.Z. and Wei B.Q. Facile Synthesis of $\mathrm{V}_{2} \mathrm{O}_{5}$ Hollow Spheres as Advanced Cathodes for HighPerformance Lithium-Ion Batteries. Materials, 2017, 10, P. 77-85.

[25] Yue Q., Jiang H., Hu Y., Jia G., Li C. Mesoporous single-crystalline $\mathrm{V}_{2} \mathrm{O}_{5}$ nanorods assembled into hollow microspheres as cathodematerials for high-rate and long-life lithium-ion batteries. Chem.Commun., 2014, 50, P. 13362-13369.

[26] Dmitriev A.V., Vladimirova E.V., Kandaurov M.V., Chufarov, A.Yu., Kellerman D.G. Magnetic properties of powders BiFe $0.93 \mathrm{Mn}_{0.07} \mathrm{O}_{3}$ powders obtained by ultrasonic spray pyrolysis. Phys. Solid State, 2017, 59, P. 2360-2364.

[27] Dmitriev A.V., Vladimirova E.V., Kandaurov M.V., Kellerman D.G., Chufarov A.Yu., Tyutyunnik A.P. Hollow spheres of BiFeO 3 : Synthesis and properties. Journal of Alloys and Compounds, 2018, 743, P. 654-657.

[28] Lyakh O.V., Eismont N.G., Surikov Wad. I., Surikov Val. I. Physical aspects of aging of vanadium (III) oxide. Omsk Scientific Bulletin, 2013, 120(2), P. 8-11.

[29] Przesniak-Welenc M., Karczewski J., Smalc-Koziorowska J., Łapinski M., Sadowskia W, and Koscielska B. The influence of nanostructure size on $\mathrm{V}_{2} \mathrm{O}_{5}$ electrochemical properties as cathode materials for lithium ion batteries. RSC Adv., 2016, 6(61), P. 55689-55697. 